\title{
Effect of Alkali Treatments of Physical and Mechanical Properties of Coir Fiber
}

\author{
Imran S. Musanif*, Adelbert Thomas \\ Department of Mechanical Engineering, Manado State Polytechnic, Indonesia
}

Copyright $(\mathcal{C} 2015$ by authors, all rights reserved. Authors agree that this article remains permanently open access under the terms of the Creative Commons Attribution License 4.0 International License

\begin{abstract}
This study aims to analyze the alkali treatment in improving the quality of the fiber as a reinforcement of natural fiber-based composite. The objects used in this study is that coconut coir fiber cross-sectional area is focused on direct measurements with the aid of a microscope Zeiss Axio Cam ICC and equipped with ZEN 2012 software as well as determining the mechanical properties without alkali treatment. The alkali treatment in the amount of $3 \%$ can decrease the surface wide of fiber to $\pm 22.78 \%$ on the soaking of 1 and 2 hours, meanwhile the soaking of 3,4 and 5 hours decrease to $\pm 31,14 \%$ from the fiber without soaking is $0,032166 \pm 0,011354 \mathrm{~mm}^{2}$. Results of testing the mechanical properties of the fiber which refers to the standard ASTM C 1557 the highest tensile strength of 147.52 $\mathrm{MPa}$ occurs on the fiber without alkali treatment and 120.85 MPa in the alkali treatment with immersion 5 hours. A decrease in physical and mechanical properties of the coco fiber due to alkali treatment caused of the release of the components of the binding between the fibers in a single fiber
\end{abstract}

\section{Keywords Alkali Treatment, Cross Section, Coir Fibre}

\section{Introduction}

Conventional fiber known (glass, aramid, carbon, etc.) has been widely used over the last few decades as a reinforcing material thermoplastic polymer matrix composites. The fibers are mixed into plastics in order to improve the mechanical properties of polymers and reduce the cost of the final product as reported by Chen [9].

Increased use of natural fiber-based material that can be renewed is one important issue to reduce the use of synthetic fiber-based composite materials. Where the use of synthetic fibers can damage the environment and bring on global climate change. As a reason, components with materials reinforced natural fibers can be decomposed by bacteria (biodegradability) so can save the environment from pollution. For that efforts continue to be made as an effort to develop a composite material that can be decomposed naturally (biocomposites) [2,8]. Josep [10] reported that the use of natural fibers is a source of abundant, variations in fiber, low cost, low density, the specific strength and high modulus.

Almeida [11] states that natural fibers can play an important role in the development of composite materials that can be decomposed by bacteria (green composites) and will be key in addressing the ecological and environmental problems. Mohanty [2] reported that structure aspects and properties of natural fibers are very varied and differ depending on location, age and type. Advantages replace synthetic fibers with natural fibers in composite materials is to reduce environmental problems, especially in ecological problems due to the natural fibers can be recycled through a heat cycle [1,6]. Vieira [5] states that natural fibers are renewable and lighter than synthetic fibers. Accordingly, Indonesia has a huge potential in the development of natural fiber-based composite materials because of its availability is very abundant which in turn can bring benefits to both economic and social.

Determination of the mechanical properties of the composite can not be separated from the mechanical properties of the fibers used as reinforcement material. Single fiber strength is determined from a tensile load to the fiber breaking divided by the fiber cross-sectional area. Assuming all along that dimension shaped fiber diameter along the fiber which is then used as a reference for determining the cross-sectional area $[23,24]$. In this study, the determination of the tensile strength of the fiber will be based on cross-sectional area by measuring directly on the fiber, so that the results achieved to become more representative.

The next issue is' how to increase the tensile strength of a single fiber?'. According to some studies, natural fiber tensile strength can be improved in two ways, namely by giving chemical treatment or by adding a coupling agent. Treatment of fibers with a chemical solution $(\mathrm{NaOH})$ is often done because it is more economical [4,7]. he above description shows that the fiber has great potential for use in 
engineering, especially as a reinforcing material of natural fiber-based composite. The mechanical properties of the composite can be enhanced by pretreatment of the fiber such as immersion in alkali $(\mathrm{NaOH})$. The result is expected to inspire other researchers to further investigate the use of a variety of natural fibers as reinforcement in view of the potential of natural fiber composites is very abundant.

\section{Materials and Methods}

\subsection{Materials}

The experiment was conducted in a test lab materials and metrology Manado State Polytechnic, 2015. The fibers obtained from coconut farmers Minahasa North Sulawesi province of Indonesia located approximately $970 \mathrm{~m}$ above sea level. Fiber is divided into two parts, namely the untreated fibers and fibers with early treatment. Fiber with initial treatment $\mathrm{NhOH}$ soaked with a solution of $3 \%$ by variasi time 1,2,3,4 and 5 hours. After soaking the fiber is washed with distilled water to remove the chemical effects after it is dried at room temperature without sunlight.

\subsection{Methods}

\subsubsection{Determining the coco fiber cross-sectional area}

Coco fiber without alkali treatment is taken at random as much as one hundred speciment. Then the fiber was given resin to harden, but before fiber inlaid such that the fibers perpendicular to the plane of the hardened resin. When dry, sanded until smooth specimen for measurement by microscope. For fibers with immersion $\mathrm{NaOH} 3 \%$ with long soaking 1,2,3,4 and 5 hours, the preparation of the test object as the manufacture of the test object on the fiber without alkali treatment. Illustration manufacture of test specimens is presented in Figure 1.

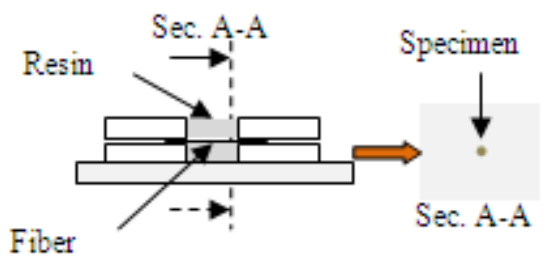

Figure 1. Illustration of making measurements of cross-sectional area of the test specimen

Fiber cross-sectional area was photographed using a Zeiss Axio microscope A1 Lab equipped with analysis tools. Enlargement is used between one hundred to two hundred times depending on the dimensions of the fiber. The amount of fiber cross-sectional area average and standard deviation using distribution Weillbul formulated as follows:

$$
F(\theta)=1-\exp \left[-\left(\frac{A}{A_{o}}\right)^{\beta}\right], 0 \leq A<\infty, \beta>0, A_{o}>0
$$

$$
\begin{gathered}
\mu=A_{o} \cdot \Gamma\left(1+\frac{1}{\beta}\right) \\
S D^{2}=A_{o}{ }^{2}\left[\Gamma\left(1+\frac{2}{\beta}\right)-\left[\left(1+\frac{1}{\beta}\right)\right]^{2}\right]
\end{gathered}
$$

Where $\mathrm{A}$ is the cross-sectional area, $\beta=$ modulus parameters, $A o=$ parameter scale $\mu=$ average value of cross-sectional area. $\mathrm{SD}=$ Standard deviation. $\Gamma=$ Function gamma. Parameter scale (Ao) specified in the condition in which In In $(\mathrm{L} / \operatorname{LF}(\mathrm{A}))=0$, while parameter form $(\beta)$ or Weibull modulus is determined slope of the relationship In In (L / LF (A) and In A.

\subsubsection{Single Fiber Tensile Test}

Single fiber tensile test is based on ASTM D 3379-75 tensile testing machine Tenso LAB instruments withdrawal force of $0.150 \mathrm{~N} / \mathrm{mim}$. Fiber test sample shown in Figure 2

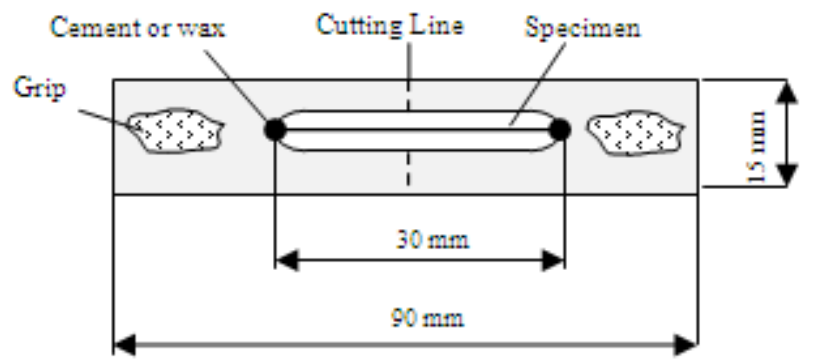

Figure 2. Single fiber tensile test (ASTM D 3379- 75)

The fiber is placed on the tab that has been established based on the dimensions of a standard ASTM D 3379-75 using glue as shown in Figure 2. Placement of the fiber in the tab should be done with caution to ensure axial fiber axis parallel to the direction of withdrawal. The tensile strength is obtained from the ratio of tensile force to break up the fiber cross-sectional area of the plane perpendicular to the fiber axis (1)

$$
\sigma=\frac{F}{A}
$$

Where $\sigma$ is tensile strength $\left(\mathrm{N} / \mathrm{mm}^{2}\right)$; $F$ is a force to failure $(\mathrm{N})$; A is fiber cross-sectional area at fracture plane $\left(\mathrm{mm}^{2}\right)$

The coir fiber Young's modulus was calculated following the procedure described in the ASTM D3379-75 Standard. Tensile tests were performed using different gauge lengths $(30 \mathrm{~mm})$. For each test, the force versus cross-head displacement curve was constructed. From the curve, the inverse of the slope of the initial linear region was obtained in $\mathrm{m} / \mathrm{N}$. By combining the Equations (2-5), we obtain (8), as follows:

$$
\begin{gathered}
\varepsilon=\frac{\Delta l}{l o} \\
\Delta L=\Delta l+C_{S} F \\
\sigma=E \cdot \varepsilon \\
\varepsilon=\frac{\sigma}{E}=\frac{F}{E A}=\frac{\Delta l}{l_{o}}
\end{gathered}
$$


where $\varepsilon$ is strain, $\Delta l$ is elongation of the gauge length, m; $l_{0}$ is gauge length, $\mathrm{m} ; \Delta L$ is recorded cross-head displacement, $\mathrm{m} ; C_{S}$ is system compliance, $\mathrm{m} / \mathrm{N} ; E$ is Young's modulus.

The combination of $(3,4)$ leads to the $(6)$ :

$$
\frac{\Delta L}{F}=\frac{\Delta l}{F}+C_{s}=\frac{l_{o}}{E A}+C_{s}
$$

Therefore, a plot of $(\Delta L / F)$ versus $\left(l_{0} / A\right)$ will yield a straight line with the constant slope of $1 / E$, as it is shown in Figure 3

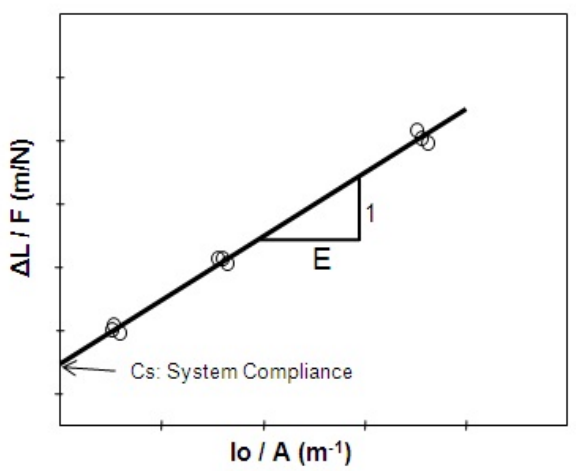

Figure 3. Determining the Young's modulus (ASTM C1557)

\section{Results and Discussion}

\subsection{Coir Fiber Broad Cross-section}

Figure 4 shows a typical cross-sectional area of coco fiber were observed using 2012 Zen software contained on the microscope Zeiss Axio Cam ICC. 1; A section is a fiber cross-section without soaking $\mathrm{NaOH}$ : $\mathrm{B}$ is a cross section of fiber with $3 \% \mathrm{NaOH}$ immersion for 3 hours and part $\mathrm{C}$ is a cross-section of the fiber by immersion $3 \% \mathrm{NaOH}$ for 5 hours
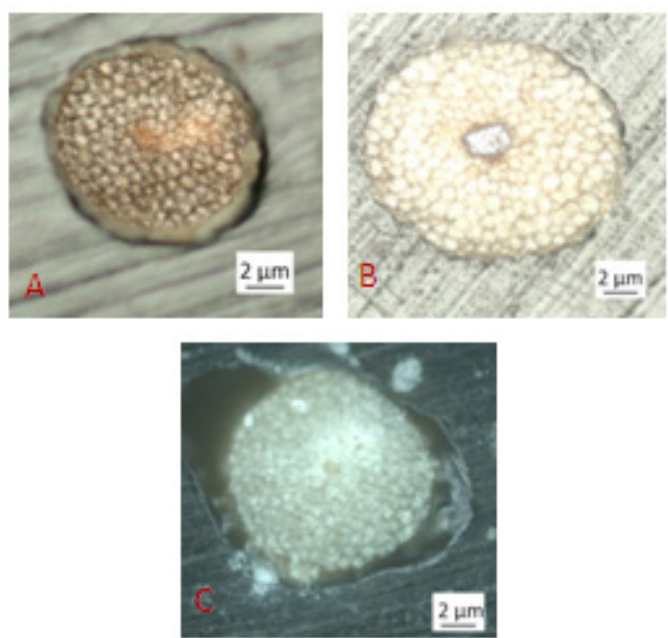

Figure 4. Typical Cross section view of single coir fiber obtained in an optical microscope using a $20 \mathrm{x}$ objective.

From the analysis of the optical microscope, coco fiber has a cross-sectional area is varied and has a spherical shape is irregular. Variabiliotas is very difficult to avoid because the natural processes that shape it. To get the average value of cross-sectional area and the standard deviation, measurement data were analyzed using the Weibull distribution and the results are presented in Table 1 below:

Table 1. Mechanical Parameters of the Coir Fibre

\begin{tabular}{|c|c|c|c|c|}
\hline \multirow{2}{*}{$\begin{array}{c}\text { Immersion } \\
\text { Time } \\
\text { (Hours) }\end{array}$} & \multicolumn{2}{|c|}{ Weibull Parameter } & \multirow{2}{*}{$\begin{array}{l}\text { Area } \\
(\mathrm{mm} 2)\end{array}$} & \multirow{2}{*}{$\begin{array}{c}\text { Standard } \\
\text { Deviation }\end{array}$} \\
\hline & $\beta$ & $\alpha$ & & \\
\hline 0 & 1,296 & 0,03595 & 0,032166 & 0,011354 \\
\hline 1 & 1,226 & 0,02222 & 0,024838 & 0,007844 \\
\hline 2 & 1,225 & 0,02217 & 0,024785 & 0,007827 \\
\hline 3 & 1,224 & 0,02476 & 0,022149 & 0,007818 \\
\hline 4 & 1,223 & 0,02470 & 0,022125 & 0,007810 \\
\hline 5 & 1,223 & 0,02475 & 0,022102 & 0,007802 \\
\hline
\end{tabular}

Table 1 shows the changes in the fiber cross-sectional area before and after the alkali treatment. Price sectional area decreases with alkali treatment, but did not provide a significant price on the length of immersion. Changes in the value of physical properties due to the alkali treatment is indicated on the Weibull modulus changes (B) or shape parameter. The larger the shape parameter values, the dissemination of data in a linear line will be greater and vice versa as shown in Figure 5 below:
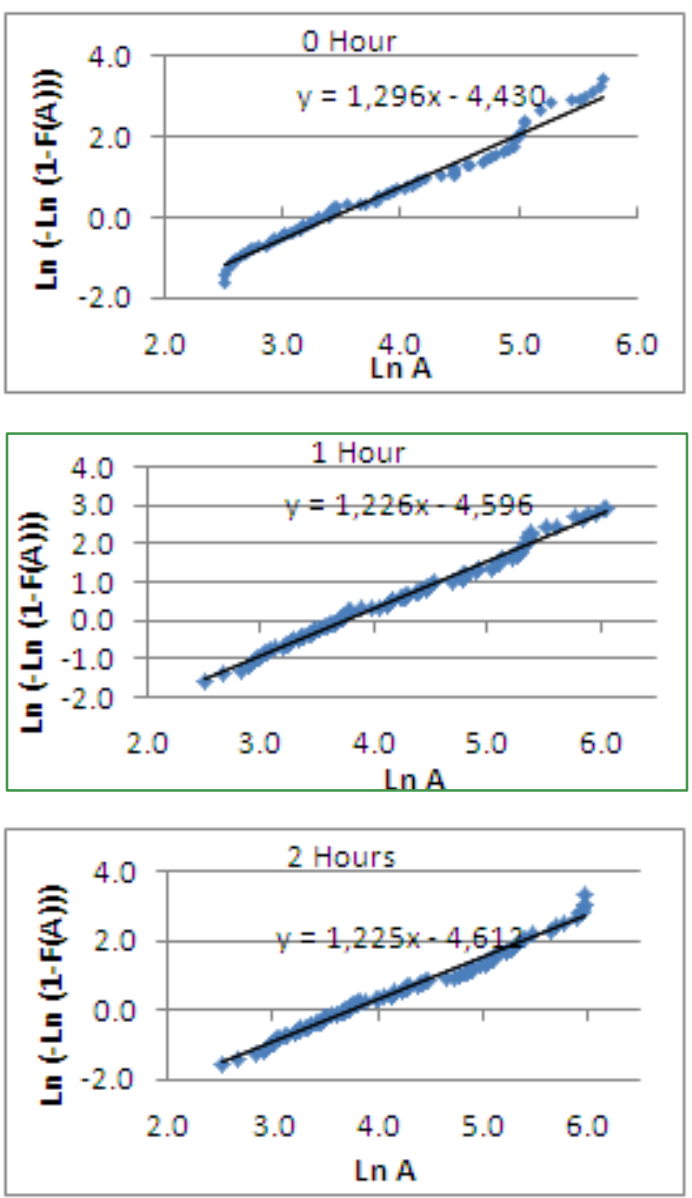

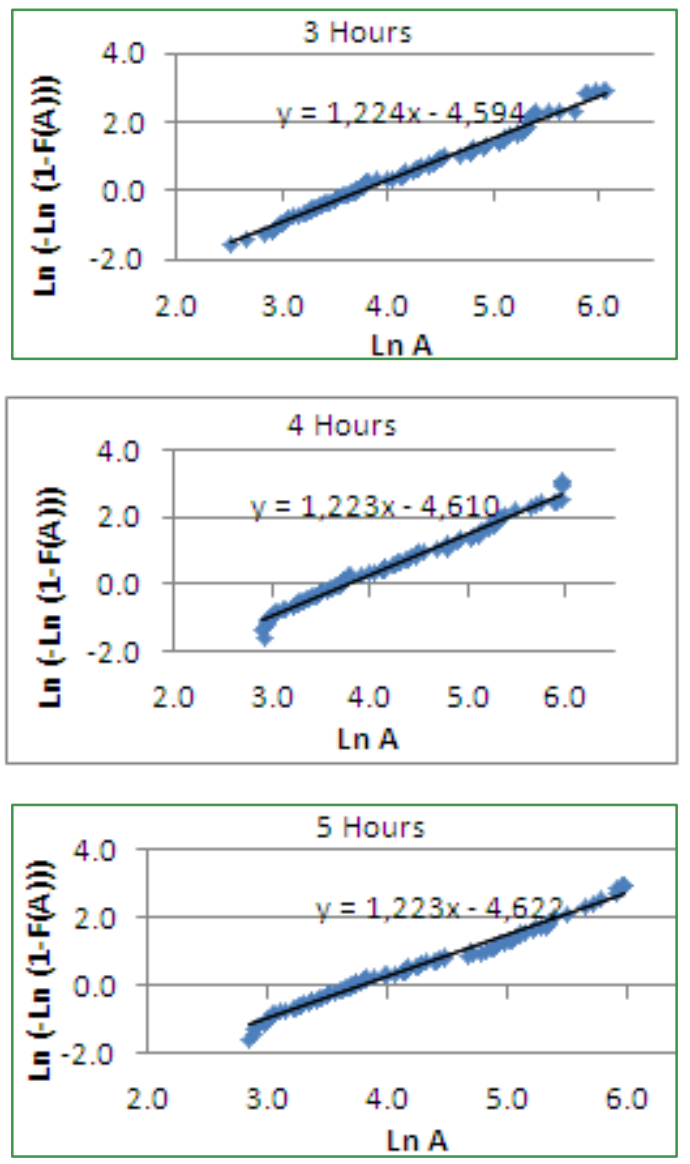

Figure 5. Weibull distribution of cross-sectional area at various times of immersion

This modulus value changes prove the influence of alkali treatment on the fiber cross-sectional area.

Munawar et.al [24] which examined some natural fibers like pineapple fiber, ramie and Sansevieria reported that after soaking the fiber becomes more alkaline cleaner because some components such as dirt, lignin and wax apart due to occur reaction between fiber and lye. The statement can be seen in Figure 4, where the fiber prior to immersion looks the color brownish between micro-fibrils that make up the composition of single fiber bond. Beside that, on the outside of the fibers visible for coating or other debris attached. While fiber is being subjected to alkaline composition between micro fibrils become brighter and the outer layer more clean. Based on Figure 4 shows that the untreated fiber alkali there are still other elements attached to the surface of the fiber that is suspected as lignin, pectin, and lilin. Carvalho et.al.[14] reported that that the surface of the fiber is covered by a layer of substances such as oils, waxes, extractive, part of the natural rules of lignocellulosic fibers.

If the cross-sectional area without alkali treatment used in this study is assumed to be circular, the diameter of the fiber of coconut coir (green fiber) is $0.2024=0.1203 \mathrm{~mm}$. These results are still representative of the research carried out by several previous studies [13-18]

\subsection{The Tensile Strength of Coco Fiber}

Fiber mechanical properties such as tensile strength $(\sigma)$, strain $(\varepsilon)$ and modulus of elasticity (E) is determined based on tensile test data and fiber cross-sectional area. To analyze the effect of alkali treatment on the mechanical properties of coco fiber, data is displayed robin curve relationship between the mechanical properties and the length of soaking in lye, as shown in Figure 6
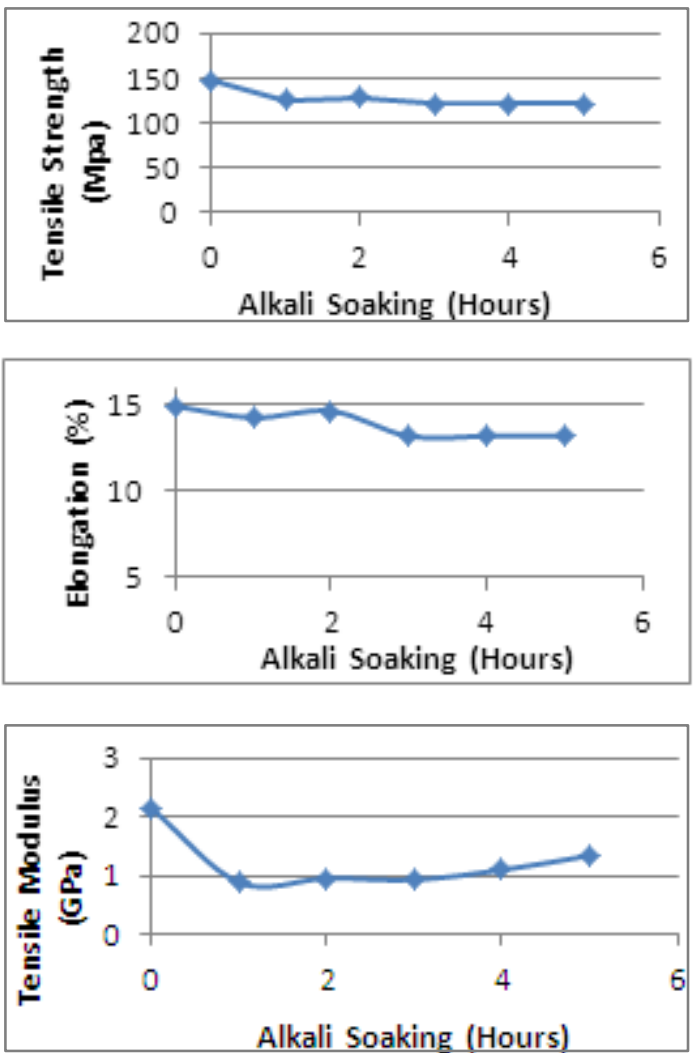

Figure 6. Curva of coir fiber tensile properties due to alkali treatment

The results showed that the lower the alkali treatment strong fiber tensile and elongation in 1 hour immersion, but at an interval of 2 hours tensile strength increases and decreases again at 3 hours soaking to achieve relatively constant conditions at the time of immersion 4 and 5 hours as shown in Figure 6. With 3\% alkali treatment on the fibers, the results showed that fiber by dipping 2 hours to produce the most optimal tensile strength. Based on the results of the microscope photograph that the results of the fiber immersion for 2 hours showed a layer of lignin and hemicellulose are being affected by degraded due to be eliminated by alkaline liquids. This is a bundle of cellulose fiber core which consists of alpha, gamma and beta cellulose, but the effect of alkali soaking for 2 hours resulted in the beta and gamma cellulose eroded. Among the three cellulose, a-cellulose is fibrous substance, which has a high tensile stress, insoluble in water, and insoluble in organic solvents. Therefore, the loss of gamma and beta cellulose fiber extension will provide optimal properties, so that the fiber tensile strength will increase. Similar results were also 
observed by $[1,3,12,21]$ which says that the alkali treatment will produce coarse fiber surface and will increase the value of the mechanical fiber. This condition is a result of the elongation of the fiber so that the fiber tensile strength increases although not the same as the fiber without treatment, while soaking 3.4, and 5 hours decreased. tensile strength and elongation caused by the damaging effects due to the alkali treatment coco fiber. A decrease in mechanical properties is due to the release of the composition that binds fibers such as Celulose, hemi-cellulose and lignin as reported Ali [21]. These results were also reported by Sgricca et.al.[22] which shows that alkali treatment can eliminate hemicellulose and lignin from the surface of the natural fiber, this indicates that the content of hemicellulose, lignin and $\alpha$-cellulose will be eroded slowly during alkali treatment.

The results of this study contrast with previous research as reported by Rosa et.al. [20] which states that the alkali treatment can increase tensile strength of approximately 53\% compared to the untreated fiber alkali. Likewise, the results of a study conducted by $[22,25]$ which concluded that the submersion of fiber will eliminate a number of hemicellulose, lignin and can erode the important elements such as gamma, beta alpha cellulose and cellulose which resulted in an increase in elongation properties / maximum strain thus giving nature optimum tensile strength.

Based on observations on the micro picture as in Figure 4, it is clear that the fiber does not experience brownish colored alkali treatment of suspected elements of the bond between the micro fibers that make up into a single fiber and the other components are attached to the fiber surface. This result is believed to be the fiber tensile strength is higher than the fiber experienced alkali treatment because micro fiber that make up a single fiber can simultaneously hold a tensile load is received. While fiber is being subjected to alkaline appear brighter that causes the binding component between micro fibers to be reduced. As a result, the tensile strength of the fiber will decrease due to the tensile load received is not distributed evenly throughout the micro fibers that make up a single fiber.

This condition gives confidence that the alkali treatment will give a strengthening effect on composite materials reinforced by coco fiber. This is quite reasonable because the fiber structure of cleaner facilitate matrix absorbs into the fiber structure to form a stronger bond.

\section{Conclusions}

Based on the results and discussion on this study it can be concluded that:

1. Cross section coco fiber has physical properties that vary and lead to a circular shape.

2. Alkali treatment causes a decrease in cross-sectional area, but did not significantly affect the immersion time.

3. The method of direct measurement of the fiber cross-sectional area is more representative to declare the performance of the mechanical properties of single fiber compared with fiber diameter measurement assuming circular fibers.

4. Treatment of alkali in the fiber gives the effect of decreasing the tensile strength of the fiber caused by the release of a binding component between micro fiber.

5. It is believed by the alkali treatment can increase the bonding between the fibers and matrix in composite materials.

\section{Acknowledgements}

We are very grateful to experts for their appropriate and constructive suggestions to improve my research in the future.

\section{REFERENCES}

[1] A. Bismarck, A.K. Mohanty, I. Aranberri-Askargorta, S. Czapla, M. Misra, G. Hinrichsenb, J. Springera. Surface characterization of natural fibers; surface properties and the water up-take behavior of modified sisal and coirfibers, Green Chemistry, Vol.3, 100-107, 2001.

[2] A.K. Mohanty, M. Misra, L.T. Drzal, Natural Fibres, Biopolymers and Biocompsites, Taylor \& Francis Group, LLC, 2005

[3] A.Choudhury, S. Kumar, B. Adhikari. Recycled milk pouch and virgin lowdensity Polyethylene/linear low-density polyethylene based coir fiber composites. Journal of Applied Polymer Science, 106(2), 775-785, 2007

[4] A.I.S. Brígida, V.M.A. Calado, L.R.B. Gonçalves, M.A.Z. Coelho. Effect of chemical treatments on properties of green coconut fiber, Carbohydrate Polymers, 79 : 832-838, 2010

[5] C.A.B. Vieira, S.B. Susisn, E. Amico Freire, E. Amico, A.J. Zattera. Characterization of Hybrid Composites Produced with Mats Made Using Different Methods. Materials Research, 12(4), 433-436, 2009

[6] E.T.N. Bisanda. The effect of alkali treatment on the adhesion characteristics of sisal fibres. Applied Composite Materials 7:331-339, 2000

[7] L.Y. Mwaikambo, M.P. Ansell. The effect of chemical treatment on the properties of hemp, sisal, jute and kapok fibres for composite reinforcement, 2nd International Wood and Natural Fibre Composites Symposium, $12.1-12.16$, 1999.

[8] L. Averous, F. Le Digabel. Properties of biocomposites based on lignocellulosic fillers, Carbohydrate Polymers, 66 (4), 480-493, 2006

[9] L.Chen, I .Chiparus, D.V. Sun, T.A. Negulescu, Calamari. Natural fibers for automotive nonwoven composites, J Industrial Textiles 35(47), 80-86, 2005

[10] K. Joseph, R.D.T. Filbo, S.Thomas , L.H. de Carvalho, , A 
Review on Sisal Fiber Reinforced Polymer Composites, Revista Brasileirade Engenharia e Ambiental, Vol. 3, No.3, 367-379, 1999

[11] J.R.M.D. Almeida, S.N. Monterio, L.A.H. Terrones. Mechanical properties of coir polyestercomposites, Elseveir Polym. Test., 27 (5) 591-595, 2008

[12] J. Rout, M. Misra, S.S. Tripathy, S.K. Nayak, A.K. Mohanty. The influence of fibre treatment on the performance of coir-polyester composites, Composites Science and Technology, 61(9), 1303-1310, 2001.

[13] J.M.L. Reis. Fracture and flexural characterization of natural fiber-reinforcedpolymer concrete, Construction and Building Materials, 20(9), 673-678, 2006.

[14] K.C.C. Carvalho,D.R. Mulinari, H.J.C. Voorwald, M.O.H. Coffi. Chemical modification effect on the mechanical properties of hips/coconut fiber composites, BioResources, 5(2), 1143-1155, 2010.

[15] K.G. Satyanarayana, K. Sukumaran, P.S. Mukherjee, C.Pavithran, S.G.K. Pillai. Natural fibre-polymer composites, Cement and Concrete Composites, 12(2), 117-136, 1990.

[16] G. Ramakrishna, T. Sundararajan. Studies on the durability of natural fibres and the effect of corroded fibres on the strength of mortar, Cement and Concrete Composites, 27(5), $575-582,2005$

[17] R.D. Toledo Filho, K. Ghavami, G.L. England. Free, restrained and drying shrinkage of cement mortar composites reinforced with vegetable fibres, Cement and Concrete Composites, 27(5), 537-546, 2005.

[18] S.S. Munawar, K. Umemura, S. Kawai. Characterized the
Morphological, Physical, and mechanical Properties of the Non-Wood Plant Fibre Bundles, J Wood Sci, 53:108-113, 2007

[19] Majid Ali. Coconut Fibre - A Versatile Material and its Applications in Engineering, Second International Conference on Sustainable Construction Materials and Technologies, 2010

[20] M.F. Rosa, B. Chiou, S.S. Medeiros, D.F. Wood, T.G. Williams, L.H.C. Mattoso, S.S. Imam. Effect of fiber treatments on tensile and thermal properties of starch/ethylene vinyl alcohol copolymers/coir biocomposites, Bioresource Technology, 100(21), 5196-5202, 2009

[21] M.M. Rahman, M.A. Khan. Surface treatment of coir (Cocos nucifera) fibers and its influence on the fibers' physico-mechanical properties, Composites Science and Technology, 67(11-12), 2369-2376, (2007).

[22] N. Sgriccia, M.C. Hawley, M. Misra. Characterization of natural fiber surfaces and natural fiber composites, Composites, 39(10), 1589-1684, 2008

[23] R.G. Raj B.V. Kokta. Compounding of cellulose fibres with polypropylene: effect of fibre treatment on dispersion in the polymer matrix, J Appl Polym Sci, 38:87-96, 1989

[24] R. H. Setyanto, Kuncoro Diharjo, I. Made Miasa, Prabang Setyono. A Preliminary Study: The Influence of Alkali Treatment on Physical and Mechanical Properties of Coir Fiber, Journal of Materials Science Research, Vol. 2, No. 4, 2013

[25] Z. Li, L. Wang, X. Wang. Cement composites reinforced with surface modified coir fibers, Journal of Composite Materials, 41(12), 1445-1457, 2007 